medRxiv preprint doi: https://doi.org/10.1101/2020.09.24.20199026; this version posted September 25, 2020. The copyright holder for this preprint (which was not certified by peer review) is the author/funder, who has granted medRxiv a license to display the preprint in perpetuity. It is made available under a CC-BY 4.0 International license .

\title{
Persistence of the T12 Vibrio cholerae 01 lineage in West Africa: Insights from a Regional Sequencing Workshop
}

\section{Eme Ekeng ${ }^{1 *}$, Serges Tchatchouang ${ }^{2 *}$, Blaise Akenji ${ }^{3}$, Bassira Boubacar Issaka ${ }^{4}$, Ifeoluwa Akintayo ${ }^{5}$, Christopher} Chukwu $^{1}$, Ibrahim Dan Dano ${ }^{4}$, Sylvie Melingui ${ }^{3}$, Ousmane Sani ${ }^{4}$, Michael Oladotun Popoola ${ }^{1}$, Ariane Nzouankeu ${ }^{2}$, Yap Boum $^{6}$, Francisco J Luquero ${ }^{6}$, Anthony Ahumibe ${ }^{1}$, Dhamari Naidoo ${ }^{7}$, Andrew S Azman ${ }^{8}$, Justin Lessler ${ }^{8}$, Shirlee Wohl ${ }^{8}$

Affiliations:

${ }^{1}$ Nigeria Centre for Disease Control, Abuja, Nigeria

${ }^{2}$ Centre Pasteur du Cameroun, Yaoundé, Cameroon

${ }^{3}$ National Public Health Laboratory, Yaoundé, Cameroon

${ }^{4}$ Centre de Recherche Médicale et Sanitaire, Niamey, Niger

${ }^{5}$ Faculty of Pharmacy, University of Ibadan, Ibadan, Nigeria

${ }^{6}$ Epicentre, Paris, France

${ }^{7}$ World Health Organization Nigeria, Abuja, Nigeria

${ }^{8}$ Johns Hopkins Bloomberg School of Public Health, Baltimore, Maryland, United States

* authors contributed equally

Abstract

We sequenced 46 Vibrio cholerae isolates from Cameroon, Niger, and Nigeria, 37 of which were from 2018-2019. These sequences belong to the T12 lineage observed in the region since 2009, suggesting continuous transmission. Data were generated during a workshop in Nigeria, providing a model for future regionally coordinated surveillance efforts. 
It is made available under a CC-BY 4.0 International license .

\section{Introduction}

Molecular characterization of pandemic Vibrio cholerae has led to new insights about global cholera transmission and has highlighted the important role of transmission within and between Asia and Africa (1). Combining genomic and epidemiological data may allow us to better understand the dynamics of ongoing outbreaks, and advances in sequencing technology have recently made whole genome sequencing more feasible even in low-resource settings.

Although recent studies have used whole genome sequences of $V$. cholerae $\mathrm{O} 1$ to better understand the global movement patterns of seventh pandemic cholera in sub-Saharan Africa and elsewhere (1-4), regional and local dynamics in West Africa — which reports cholera regularly—are still poorly understood. Epidemiological data suggest outbreaks across this region may be connected (5-7), but the nature of recurring outbreaks in the region has yet to be understood. It is unclear if cases go unreported in years between outbreaks or if each represents a distinct pandemic $V$. cholerae introduction from outside the region. Discerning between these two transmission scenarios is important for the development of locally-adapted and effective cholera control and prevention strategies.

Here we focus on the 2018-2019 cholera outbreaks in three countries with endemic cholera - Cameroon, Niger, and Nigeria - to understand what $V$. cholerae sequence data from these outbreaks can tell us about transmission patterns within the region. These three countries all reported large numbers of cholera cases during this time period $(2,066,3,083$, and 32,752, respectively) $(8,9)$ after several years of reported low cholera incidence (Fig 1A). Broad sequencing of historical $V$. cholerae isolates included 45 sequences from Cameroon from 1970-2011, 15 sequences from Niger from 1970-2010, and 22 sequences from Nigeria from 1970-2014 (1,2). The specific lineage of $V$. cholerae circulating in each country, determined from the genomic data, provides important information about the movement of the disease.

Previous studies have shown that the T1 lineage was the predominant lineage circulating in Cameroon, Nigeria, and Nigeria in 1970, followed by the T7 and T9 lineages in the 1990s and early 2000s (1,2). Since 2009, only T12 has been observed in these countries, and this appears to be the predominant lineage in Western Africa and nearby countries in Central Africa. In any given year, the circulating $V$. cholerae lineage was the same in Cameroon, Niger, and Nigeria $(1,2)$, providing additional evidence that outbreaks in these countries are connected. As five years had elapsed since the last published $V$. cholerae $\mathrm{O} 1$ genome in the region, we aimed to generate a contemporary snapshot of recent $V$. cholerae $\mathrm{O} 1$ outbreaks to determine if recent cases were due to a new introduction of the pathogen, and to gain new insights into regional cholera transmission dynamics and spread of antibiotic resistance. 
A
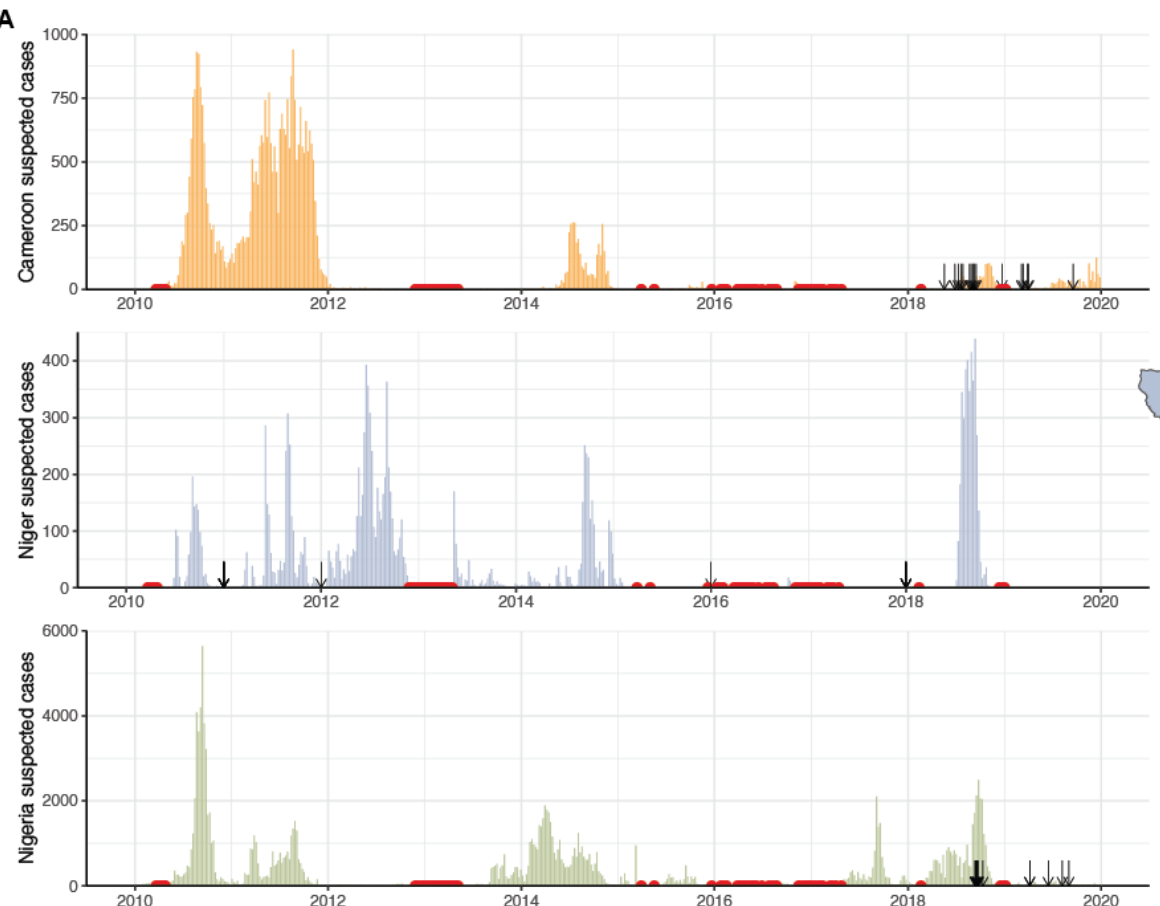

B

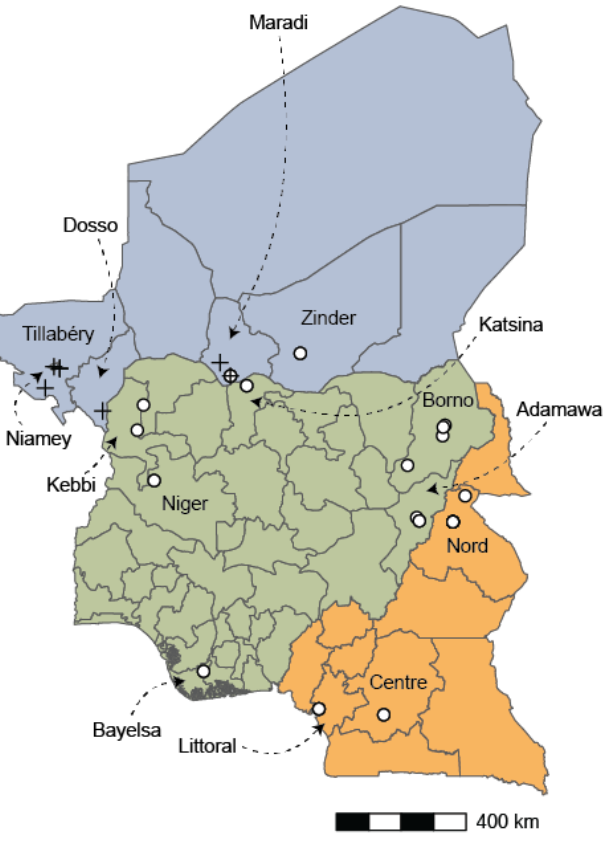

Figure 1. Cholera cases and sequenced isolates. (A) Weekly reported suspected cholera cases for Cameroon (orange), Niger (blue) and Nigeria (green) from 2010 through 2019 (8). Red points: weeks with no more than five suspected cases reported across all three countries. Arrows: collection dates of isolates sequenced. Collection dates provided as year only are plotted on January 1 of their given year. (B) Map of Cameroon, Niger, and Nigeria. Colors are as in (A). White points: location of sequenced isolates collected in 2018-2019. Black crosses: location of sequenced isolates collected prior to 2018 . Two isolates with unknown sub-country locations are not shown.

\section{The Study}

In October 2019, researchers from Cameroon, Niger, Nigeria, and the United States came together to discuss the specific cholera surveillance questions in these African countries and how whole genome sequencing can be used to address them. Simultaneously, researchers generated whole genome sequences from $V$. cholerae isolates collected in these countries and discussed plans for building a regional cholera genomics network to help inform cholera preparedness and outbreak response.

A key component of this workshop was bringing together detailed epidemiological data from the three countries and using this to select $V$. cholerae isolates for sequencing that captured the 2018-2019 outbreak over time and space. We also prioritized isolates from locations near the borders between the three countries, in order to increase the likelihood of capturing evidence of cross-border transmission. We selected 46 isolates from clinical and lab confirmed cases for sequencing (16 from Cameroon, 15 from Niger, 15 from Nigeria), 37 of which were from 2018-2019 cases (Fig 1B, Appendix Table 1).

We sequenced extracted DNA from these isolates on the Oxford Nanopore MinION and assembled genomes by aligning the resulting sequencing reads to the seventh pandemic O1 reference genome, strain N16961 (GenBank 
accession: AE003852/AE003853) (1,10). We also performed antimicrobial resistance (AMR) gene detection on these sequences and compared the results to previously published sequences.

Forty-four genomes produced reference-based assemblies (covering at least 95\% of the N16961 reference at $>100 x$ coverage, Appendix Table 2). We aligned these genomes to 1280 previously-published $V$. cholerae $\mathrm{O} 1$ whole genome sequences $(1,2,11,12)$ and generated a maximum likelihood tree from these data, which showed that all 44 isolates belong to the T12 lineage. Two sequenced isolates did not align to the reference (NGA_148_2019, NGA_252_2019), and we found that the reads did not map to the wbe or $w b f$ gene clusters associated with the O1 and $\mathrm{O} 139$ serogroups, respectively (or the $c t x A$ cholera toxin) (13). These results are concordant with laboratory testing performed in Nigeria, which designated these isolates as non-O1 $V$. cholerae. AMR profiles were similar to previously published sequences from this region, though we detected new mutations in genes ( $g y r A$ and $g y r B$ ) associated with quinolone resistance (see Appendix for detailed experimental methods and AMR results).

\section{Conclusions}

We did not find evidence for a new introduction of $V$. cholerae $\mathrm{O} 1$ between 2014 - the date of the last published isolate from these countries - and 2018. On the contrary, we found evidence for evolution of the bacterium within the region: all isolates from 2018-2019 (as well as the 2011-2016 isolates from Niger) fall within the T12 lineage, and the 2018-2019 sequences are part of a sub-clade containing 2014 and 2016 isolates from countries in West Africa (Fig 2). Within this sub-clade, the 2018-2019 sequences are distinct. In concordance with the epidemiologic data, the high similarity between sequences (including shared mutations in known AMR genes, see Appendix Table 3 and 4) from the three countries suggests that their outbreaks are linked.

The phylogeny also suggests that nearby countries such as Ghana and Togo may have outbreaks connected to those in Cameroon, Niger, and Nigeria, though it is unclear just how far this cholera transmission region extends. As of this writing, there are no published $V$. cholerae $\mathrm{O} 1$ genomes from the nearby countries of Benin, Burkina Faso, or Mali, for example, from after 2010. Sequences from Central African Republic, South Sudan and Democratic Republic of the Congo from 2011-2018 suggest that the T10 lineage is predominant in Central Africa (2,12), but more recent data are needed to delineate the boundary between T10 and T12 circulation. 


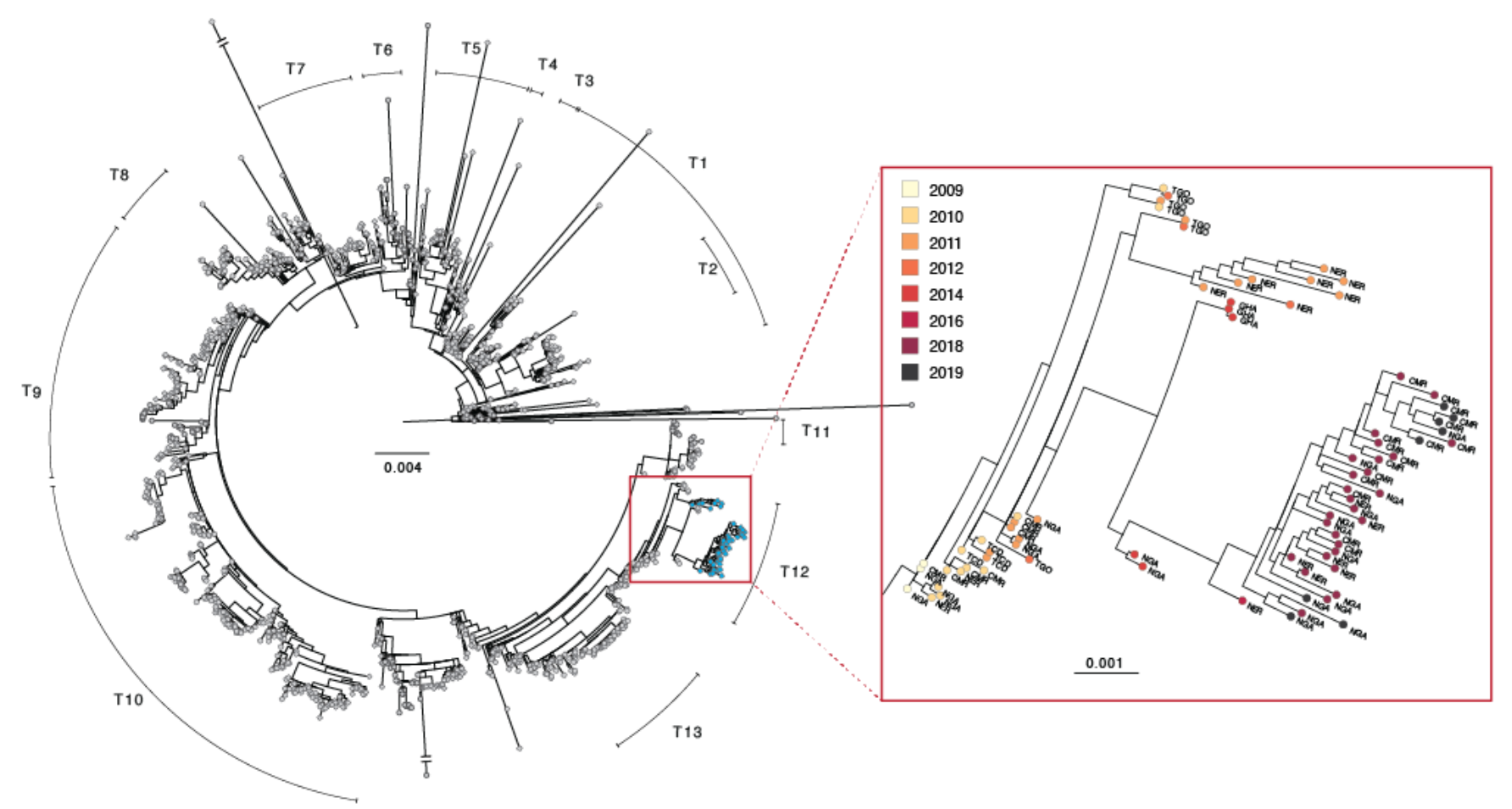

Figure 2. Phylogenetic tree of $\boldsymbol{V}$. cholerae 01 sequences. Left: maximum likelihood tree of global $V$. cholerae isolates. Samples generated in this study are shown in blue. Right: zoom view of a portion of the T12 lineage containing $V$. cholerae genomes generated in this study. Country codes: TGO, Togo; NER, Niger; GHA, Ghana; CMR, Cameroon; NGA, Nigeria; TCD, Chad. Scale bar unit: nucleotide substitutions per site.

Even so, there is strong evidence that, at least in Cameroon, Niger, and Nigeria, T12 V. cholerae was present throughout 2009-2019, even though there were few reported cases in 2014-2017. This could be explained by underreporting or under-diagnosing of cases, movement of the same cholera lineage in and out of these countries during that time period, or an environmental reservoir of $V$. cholerae in the region (such as Lake Chad, though prior studies have provided evidence against this (14)) that is responsible for repeated reintroduction of the same lineage back into the population.

Expanded surveillance and additional sequencing data will be necessary to understand the interconnectedness of populations across countries and achieve global elimination goals such as those outlined in the GTFCC Roadmap. For example, limiting cross-border movement is an ineffective strategy in the presence of a natural reservoir responsible for repeated reintroduction. Additionally, sequencing data can be used to detect and track resistance to antibiotic treatments, and to identify potential new resistance-conferring mutations present in local isolates (15). A regional cholera surveillance network could facilitate efforts to gather isolates, build the local capacity needed to generate sequencing data, and ensure that these data are interpreted within the regional context. As a result of the workshop, scientists from Cameroon, Niger, and Nigeria have all been trained in $V$. cholerae sequencing with the Oxford Nanopore MinION platform; expanding sequencing knowledge and capacity beyond these three countries will make it easy to generate the data needed to control cholera outbreaks in the region. 
medRxiv preprint doi: https://doi.org/10.1101/2020.09.24.20199026; this version posted September 25, 2020. The copyright holder for this preprint (which was not certified by peer review) is the author/funder, who has granted medRxiv a license to display the preprint in perpetuity. It is made available under a CC-BY 4.0 International license .

\section{Acknowledgements}

129 This project was made possible by the Nigeria Centre for Disease Control, who graciously hosted researchers at the 130 National Reference Laboratory in Abuja, Nigeria for training and $V$. cholerae sequencing. We thank Aicha Omar 131 for laboratory assistance and strain isolation, Alama Keita and the West Africa Cholera Platform for sharing 132 incidence data, David Mohr for laboratory assistance and space, and Daryl Domman for providing $V$. cholerae 133 alignments used as a background phylogenetic dataset. We also thank the original authors of the sequences used in 134 this background dataset (references provided in Appendix). Funding for this project was provided by Bill and 135 Melinda Gates Foundation OPP1195157. 


\section{References}

1. Weill F-X, Domman D, Njamkepo E, Tarr C, Rauzier J, Fawal N, et al. Genomic history of the seventh pandemic of cholera in Africa. Science. 2017 Nov 10;358(6364):785-9.

2. Weill F-X, Domman D, Njamkepo E, Almesbahi AA, Naji M, Nasher SS, et al. Genomic insights into the 2016-2017 cholera epidemic in Yemen. Nature. 2019 Jan;565(7738):230-3.

3. Mutreja A, Kim DW, Thomson NR, Connor TR, Lee JH, Kariuki S, et al. Evidence for several waves of global transmission in the seventh cholera pandemic. Nature. 2011 Aug 24;477(7365):462-5.

4. Domman D, Quilici M-L, Dorman MJ, Njamkepo E, Mutreja A, Mather AE, et al. Integrated view of Vibrio cholerae in the Americas. Science. 2017 Nov 10;358(6364):789-93.

5. UNICEF. Cholera Epidemiology and Response Factsheet Niger [Internet]. 2013. Available from: https://www.unicef.org/cholera/files/UNICEF-Factsheet-Niger-EN-FINAL.pdf

6. UNICEF. Cholera Epidemiology and Response Factsheet Nigeria [Internet]. 2013. Available from: https://www.unicef.org/cholera/files/UNICEF-Factsheet-Nigeria-EN-FINAL.pdf

7. UNICEF. Cholera Epidemiology Response Factsheet Cameroon [Internet]. 2013. Available from: https://www.unicef.org/cholera/files/UNICEF-Factsheet-Cameroon-EN-FINAL.pdf

8. Regional Cholera Platform in West and Central Africa [Internet]. Available from: https://www.plateformecholera.info/index.php/cholera-in-wca/

9. Nigeria Centre for Disease Control. National Monthly Update for Cholera in Nigeria. 1 November, 2019. Report No.: 05.

10. Clark K, Karsch-Mizrachi I, Lipman DJ, Ostell J, Sayers EW. GenBank. Nucleic Acids Res. 2016 Jan 4;44(D1):D67-72.

11. Bwire G, Sack DA, Almeida M, Li S, Voeglein JB, Debes AK, et al. Molecular characterization of Vibrio cholerae responsible for cholera epidemics in Uganda by PCR, MLVA and WGS. PLoS Negl Trop Dis. 2018 Jun;12(6):e0006492.

12. Irenge LM, Ambroise J, Mitangala PN, Bearzatto B, Kabangwa RKS, Durant J-F, et al. Genomic analysis of pathogenic isolates of Vibrio cholerae from eastern Democratic Republic of the Congo (2014-2017). PLoS Negl Trop Dis. 2020 Apr;14(4):e0007642.

13. Greig DR, Schaefer U, Octavia S, Hunter E, Chattaway MA, Dallman TJ, et al. Evaluation of Whole-Genome Sequencing for Identification and Typing of Vibrio cholerae. J Clin Microbiol [Internet]. 2018 Nov;56(11). Available from: http://dx.doi.org/10.1128/JCM.00831-18

14. Debes AK, Ateudjieu J, Guenou E, Ebile W, Sonkoua IT, Njimbia AC, et al. Clinical and Environmental Surveillance for Vibrio cholerae in Resource Constrained Areas: Application During a 1-Year Surveillance in the Far North Region of Cameroon. Am J Trop Med Hyg. 2016 Mar;94(3):537-43.

15. Mashe T, Domman D, Tarupiwa A, Manangazira P, Phiri I, Masunda K, et al. Highly Resistant Cholera Outbreak Strain in Zimbabwe. N Engl J Med. 2020 Aug 13;383(7):687-9. 